\title{
Patterns of productivity changes in nursing homes by using Malmquist DEA index
}

\author{
Josipa Višić* and Lana Kordić \\ Faculty of Economics, Business and Tourism \\ University of Split, Cvite Fiskovića 5, 21000 Split, Croatia \\ E-mail:〈\{josipa.visic, lana.kordic\}@efst.hr〉
}

\begin{abstract}
Motivation to open a for-profit nursing home is the same as motivation to start any other business, and it seems that, due to various demographic and social changes, the interest in this sector, especially in developed countries, will increase in the future. In that context, this research aims to analyze the efficiency of for-profit nursing homes with a focus on Croatian for-profit nursing homes from 2015 to 2019. In order to estimate different kinds of efficiencies, precisely to estimate technological change, which can't be estimated through windows DEA, and technical efficiency changes, the Malmquist - DEA performance measure was chosen for this analysis. The results show that for-profit nursing homes in our sample experienced an increase in the total factor productivity by $12.67 \%$ in the analyzed period, where the decline in technical efficiency $(-0.21 \%)$ was compensated by an increase in technological change $(13.16 \%)$. Although technological innovation shifted the relative efficient frontier to a higher level, for-profit nursing homes in our sample were far from the best production frontier, highlighting managerial inefficiency.
\end{abstract}

Keywords: data envelopment analysis, for-profit nursing homes, Malmquist index, panel data

Received: November 25, 2021; accepted: December 7, 2021; available online: December 23, 2021

DOI: $10.17535 /$ crorr.2021.0013

\section{Introduction}

Silver economy, which is related to all economic activities, products and services designed to meet the needs and demands of people over 50 [4], might be just a new buzzword but data on population age structure indicate that the aging process will change the way in which we analyze various economic concepts. Namely, almost a quarter $(24.52 \%)$ of the global population is 50 and over, and in Europe, this portion is significantly higher (39.91\%) [26]. When we observe data on adults over 65 , who globally account for $9.56 \%$ and in Europe $19.46 \%$ of the whole population, it is understandable why along with gerontology, that studies physical, mental and social implications of aging [9], gerontechnology evolved as well. Silver economy, gerontology, and gerontechnology (which is focused on designing technology and environment for independent living and social participation of older people [10]), serve as a framework for analyzing nursing homes for older people which is the main focus of this research.

Activities of nursing homes can be analyzed from many different angles and are a prolific scientific niche. General trends suggest that the population is getting older, life expectancy is longer, fertility rates are lower and the structure and size of a family alters and all these changes increase the demand for nursing homes, especially in developed countries. The aforementioned changes have macroeconomic implications which become evident in the form of higher health

${ }^{*}$ Corresponding author. 
and social care expenditures, increased burden on the public pension system, workforce shortage, and even lower productivity of workers whose elderly family members are not properly taken care of. Furthermore, nursing home business has various effects on both the private and public sector since at the same time it can: (a) satisfy the growing demand for accommodating the elderly, (b) create new jobs for many workers from different professions, (c) contribute to the state budget, and (d) raise the quality of life for both its users and their families. Therefore, this paper acknowledges the importance of various aspects of the nursing home business but is directed solely to a particular microeconomic aspect, i.e. to the efficiency of this business.

Over the years, efficiency of nursing homes has been mainly analyzed by using Data Envelopment Analysis (DEA) and to a minor extent by using Stochastic Frontier Analysis (SFA) (for detailed literature overview cf. [14] and [25]). Regarding the sample, these studies mainly address nursing homes in the USA, Canada, Taiwan, and several highly developed European countries [25]. An insight into variables used to detect efficiency of nursing homes reveals that authors mainly used number of beds, number of nursing/non-nursing employees and labor price as input variables, while number of residents' days was most often used as an output variable. To the authors' best knowledge, solely $[11,12]$ and [27] use at least one financial indicator as an input or output variable. In 1992, [11] analysed 22 nursing homes in Kansas in outputoriented DEA analysis, while [27] investigated efficiency in 2012 and 2013 for 96 non-profit nursing homes in Portugal by using input-oriented DEA and Tobit regression. On the other hand, [12] used input-oriented DEA to analyze the efficiency of 41 Croatian for-profit nursing homes in 2019. Therefore, this paper contributes to the field in several ways. First, it provides a unique microeconomic perspective on nursing homes business by focusing on for-profit homes and using financial variables. Namely, the demand for this type of service is growing, and the whole observed economic system and owners of these homes benefit from efficient use of resources. Therefore, a study evaluates the efficiency of for-profit homes in terms of generating profit, while in order to follow the production process proxies, three standard factors of production are used as inputs. In other words, this paper emphasizes the importance of studying nursing homes business as any other investment opportunity without neglecting the importance of services they provide for their users, their families, and the whole society. Second, in order to monitor efficiency over time, the paper provides a critical theoretical analysis of the Malmquist index and Window analysis, arguing for the use of the Malmquist index. Namely, according to [19] one of the main features of the DEA Malmquist index is that despite measuring the change in efficiency over time, it presents two additional pieces of information that relate to the change in technical efficiency and technology. According to this information, it is possible to analyze the catching-up effect and innovation. Finally, besides theoretical and methodological contribution, by focusing solely on Croatian for-profit nursing homes, the paper provides an insight into characteristics of this business activity in under-analyzed European countries. Hence, the obtained results are valuable to managers of nursing homes, both those for-profit and non-profit since the demand for this service is increasing and it is in their best interest to rationalize their resources. Furthermore, resource efficiency, especially in an activity that has multiple social implications is important for policymakers, as well.

The remainder of the paper has the following structure. The second section describes the sample and observed variables, as well as gives an overview of the used methodology. The third section presents results and accompanying discussion while the conclusion is given in the fourth section. 
Patterns of productivity changes in nursing homes by using Malmquist DEA index

\section{Methodological framework}

\subsection{Data description}

As already stated, the population in Europe is in general older than elsewhere in the world, and data on age structure suggest that the situation in Croatia is even more alarming. Around $42 \%(42.52 \%)$ of the population is 50 and over, while $21.31 \%$ is 65 and older [3]. Along with the aforementioned trends related to fertility rates, family structure, and life expectancy, aging is an important factor for the Croatian economy in various ways but the focus of this paper is solely on nursing homes business. All these changes in population and society increase the demand for nursing homes and it seems this trend will continue. Namely, in Croatia there are four types of accommodation for the elderly: (1) foster family - maximum of 4 people can be accommodated in a single foster family; (2) family home for the elderly - it can accommodate up to 20 people in one household; (3) home for elderly which is not established as an institution - an association, religious community, company, and other domestic and foreign legal entities, as well as an individual, in addition to performing the main activity for which it is registered, can provide this social service; (4) home for the elderly (a social welfare institution) - a public institution that may be established by the Republic of Croatia, unit of local and regional government (decentralized homes), religious community, company, association, and other domestic and foreign legal entities.

In Croatia, there are accommodation capacities for 29,414 or $3.68 \%$ of people aged 65 and over, which is far lower than the EU average of $5 \%$ [28]. There are just two state nursing homes (with 168 users) and 45 decentralized nursing homes (with 10,947 users in 2020) [21]. On the other hand, on 31 December 2019, 431 family homes were operating, with a capacity for 10,222 users and there were 106 non-state homes for the elderly with a capacity for 6,458 users [21]. Along with the fact that the number of state and other decentralized homes has stayed the same for years, the government plans to abolish family homes over the next 5 years (and as an alternative, they offer to provide this service as foster care or via the establishment of an institution for the care of the elderly). Therefore, it is reasonable to expect that number of nursing homes in private ownership will raise in Croatia even though there is a trend in developed countries to decrease institutionalized accommodation for the elderly. Namely, the aim is to establish a support system so that the elderly can continue to live in their own homes and get help in different aspects of their everyday life.

The Croatian Ministry of Labor, Pension System, Family and Social Policy publishes a list of legal entities providing social services [15] and the Croatian Chamber of Commerce [5] provides information on legal entities operating in Croatia and we used these two sources to gather data for this research since we analyzed for-profit nursing homes in Croatia. As the number of private limited liability companies is raising over the years (e.g. in autumn of 2021 there were 42, which is an increase by approximately $17 \%$ when compared to spring 2021 and the number of simple private limited companies was 38 , which is an increase by approximately $23 \%$ in the same period) we choose to observe for-profit nursing homes that have been operating through the whole period from 2015 to 2019. Because of this requirement regarding the observed period, the sample is further reduced to 16 for-profit nursing homes in order to satisfy the rules of the methodology used, i.e. a unit (nursing home) is included in the sample only if all of its observed data differs from zero. Namely, the Malmquist DEA index is used to analyze the efficiency change of for-profit nursing homes in Croatia in the period $2015-2019$.

Furthermore, variables in this study were selected in a way that represents the efficiency of nursing homes observed from an investment opportunity aspect, i.e., we selected financial variables following [11] and [27] that are focused on the same sector, yet we found confirmation for this decision in studies of a similar sector, such as private hospital sector [6] or other sectors, such as in $[2,22]$ and [30]. More precisely, the output is presented through revenues, 
while in order to follow the production process, proxies for standard microeconomic factors of production (land, labor, and capital) are used as inputs. Along with aforementioned studies, that served as a ground point for selecting input and output variables, the fact that there are no publicly available data on other business aspects of for-profit nursing homes in Croatia plays an important role in establishing the DEA model. Namely, there are no publicly available data on the number of beds, number of medical and non-medical staff in each home, etc.

The data set for measuring the efficiency of for-profit nursing homes, presented in Table 1, consist of three inputs (tangible assets, staff costs, and material costs) and one output (total revenue).

\begin{tabular}{|l|rrrr|}
\hline Variable & \multicolumn{1}{|c}{ Mean } & Standard deviation & Minimum & Maximum \\
\hline \hline Inputs: & & & & \\
Tangible assets & $510,677.28$ & $1,065,163.50$ & $1,552.00$ & $4,316,154.00$ \\
Staff costs & $350,329.75$ & $271,853.05$ & $46,511.00$ & $1,699,280.00$ \\
Material costs & $297,997.40$ & $277,006.44$ & $2,995.00$ & $1,444,258.00$ \\
Output: & & & & \\
Total revenues & $759,999.68$ & $671,704.79$ & $109,681.00$ & $3,508,298.00$ \\
\hline
\end{tabular}

Table 1: Descriptive statistics of selected variables in period 2015-2019.

\subsection{Specification of DEA model}

Performance can be defined as a suitable combination of efficiency and effectiveness. According to [18], the beginnings of microeconomic efficiency theory started in 1950 when Koopmans first defined technical efficiency. As mentioned in [19], efficiency is defined as the ratio used for production factors, i.e. inputs and outputs. Accordingly, activity is efficient if it for a given level of inputs produces a greater amount of outputs or if it for a certain amount of outputs uses fewer inputs. On the contrary, effectiveness refers to using minimum inputs for a given number of outcomes, and it includes the dimension of quality. Seven years after the first definition of efficiency, Farrell defined how to measure it [19]. Even though methodology for measuring efficiency has been constantly improving ever since, its effective application on public services has remained a conceptual challenge.

As mentioned before, in order to set the efficiency frontier, different statistical and mathematical approaches can be applied. The statistical approach is based on econometric models and has the characteristics of stochasticity (randomness), while the mathematical approach is based on the models known as linear programming and is deterministic by nature. Those two approaches differ in the way they define the efficiency frontier and how they interpret the observed units that deviate from the frontier. More precisely, the econometric approach aims to determine the absolute efficiency in relation to the set benchmark. The deviations can be the result of random error, which is normally distributed, and inefficiency, which is asymmetrically distributed. More precisely, the deterministic frontier approach (DFA) takes all deviations from the border as a result of inefficiency, where its major disadvantages are the difficulty in including more outputs in analysis and the fact that it requires a large sample. The stochastic frontier approach (SFA) solves the biggest drawback of the DFA by taking into account the existence of external factors, while the problem of an assumption of normal distribution still remains [29].

As opposed to statistical approaches, whose objective is to determine the absolute efficiency of the observed unit in relation to an idealized comparison with the standards, mathematical programming analyzes relative efficiency in relation to other units within the same network. In order to evaluate relative efficiency, Data Envelopment Analysis (DEA) is the most commonly 
used tool for linear programming. By determining relative efficiency, all deviations from the frontier are treated as inefficient [7]. Furthermore, it does not require specific functions of providing services. Namely, the formulation of production is based on inputs and outputs, where the non-parametric bases and freedom to process multiple inputs and outputs with different units, resolve the problem of measurement data required for an econometric approach. Because of all the aforementioned, DEA has become the dominant approach for measuring efficiency in many economic sectors [16] and is thus used in this study.

The first step of the DEA approach is to select a model for assessing efficiency. Types of DEA models can be defined based on the scale and orientation of the model. As explained in [7], basic models are Charnes - Cooper - Rhodes (CCR) model (1978), and Banker - Charnes Cooper (BCC) model (1984). The CCR model assumes a constant rate of substitution between inputs and outputs (CRS), while the BCC assumes an existing economy of scale (VRS). Both models can be oriented towards output maximization or input minimization.

As owners of for-profit nursing homes have higher control over the inputs than their outputs, and because they prefer to provide care by using their resources in a least costly way, our analysis required the implementation of an input-oriented DEA model. Moreover, most studies dealing with nursing homes used solely input-oriented models (according to [14] 11 out of 14 analyzed studies). Furthermore, to implement an appropriate model according to returns to scale, overall technical efficiency (OTE) (running CCR input-oriented model) and pure technical efficiency (PTE) (running BCC input-oriented model) for 2019 were calculated. Furthermore, the scale efficiency (SE) is calculated as the ratio of OTE to PTE [17]. This step is a precondition for the following analysis because the CRS assumption is valid only if the SE score is equal to one [8].

\begin{tabular}{|c|rrr|c|rrr|}
\hline DMUs & OTE & PTE & SE & DMUs & OTE & PTE & SE \\
\hline \hline NH1 & 0.8938 & 1 & 0.8938 & NH9 & 0.9509 & 1 & 0.9509 \\
NH2 & 0.6628 & 0.6652 & 0.9964 & NH10 & 0.898 & 0.9798 & 0.9165 \\
NH3 & 1 & 1 & 1 & NH11 & 0.8651 & 1 & 0.8651 \\
NH4 & 0.8551 & 0.9124 & 0.9372 & NH12 & 0.9865 & 0.9925 & 0.9940 \\
NH5 & 0.7194 & 0.7231 & 0.9949 & NH13 & 0.8464 & 0.8823 & 0.9593 \\
NH6 & 0.8026 & 0.8042 & 0.9980 & NH14 & 1 & 1 & 1 \\
NH7 & 1 & 1 & 1 & NH15 & 1 & 1 & 1 \\
NH8 & 0.7275 & 0.7346 & 0.9903 & NH16 & 1 & 1 & 1 \\
& & & & Mean & 0.8880 & 0.9184 & 0.9763 \\
\hline
\end{tabular}

*Database with names of nursing homes is available upon request

Table 2: Overall, technical and scale efficiency of Croatian for-profit nursing homes in 2019.

According to results presented in Table 2, Croatian for-profit nursing homes did not operate on the scale fit to their capacities, i.e. they were not successful in delivering their services at optimal scale. Within the presented theoretical framework, in the following analysis an emphasis is placed on PTE (without scale efficiency) by comparing for-profit nursing homes only to other nursing homes of similar scale, by highlighting managerial inefficiency, i.e. the input-oriented BCC model was chosen for this analysis.

\subsection{Panel evaluations}

In order to quantify the evolution of efficiency over a period of time, i.e. to measure efficiency through cross-sections and variable data over time, a DEA window analysis (WDEA) and the Malmquist productivity index (MI) can be used. Namely, DEA analysis has a stationary character, and those two analyses resolve this weakness. Contrary to cross-sectional data, which 
provide a snapshot of producers and their efficiency, panel data provide more reliable evidence on their performance by tracking the performance of each producer through sequence periods [24].

According to [23], WDEA was first introduced by Charnes and Cooper (1985), whereby the relative efficiency was measured for models with a small sample size over time (e.g., [23] used window analysis to analyze five Spanish electricity distribution firms between 2006-2015, while [1] applied DEA window analysis to measure the efficiencies of two packaging lines in the Penicillin plant in a Jordanian Medical Company from April to October 2010). It evaluates the performance of a decision-making unit (DMU) over time by treating it as a different entity in each period. That is, it allows the comparison of each DMUs against itself and other DMUs. Moreover, according to [13], WDEA can be used to address the issue of the lower degree of freedom in DEA, when the number of DMUs is lower than the number of inputs and outputs.

On the other hand, MI provides an opportunity to compare the nursing home's performance from one period to another [20]. According to [19], MI was suggested by Malmquist in 1953, then developed by Caves et al. in 1982 as a productivity index, and finally developed by Fare et al. in 1994 as the Malmquist - DEA performance measure. MI can decompose the overall efficiency measure into two components, one measuring the change in technical efficiency (EFFCH) and the other measuring change in technology (TECHCH). More precisely, the first component measures change in technical efficiency from one period to another, i.e. it measures how the DMU has managed to catch up to the relatively efficient frontier. Furthermore, the second component measures changes in the efficient frontier from one period to another. By analyzing those two components, it is possible to identify whether the identified changes from one period to another are due to pure efficiency improvement, technological changes in service delivery (whether they are related to certain innovation in the production process, which caused a shift in the efficiency frontier) or are the consequence of both these changes.

In order to estimate different kinds of efficiencies, precisely to estimate technological change which can't be estimated by using WDEA, the MI was chosen for this analysis. Namely, when inefficiency exists, the relative movement of any given DMU over time depends on both its position relative to the corresponding frontier and the position of the frontier itself.

\section{Results and discussion}

Table 3 presents the technical efficiency scores obtained from the input-oriented BCC model for 16 for-profit nursing homes $(\mathrm{NH})$ and their distribution, while the efficiency analysis was conducted using the computer software Frontier Analyst Banxia Software.

DEA forms a frontier using the efficient DMUs. They receive a score of 1 and those that are not on the efficient frontier, have a score between 0 and 1 . As it can be observed, the mean technical efficiency scores of for-profit nursing homes in Croatia indicate a decrease in 2016 relative to 2015 and in 2019 relative to 2018 and an increase in 2017 and 2018 relative to 2016 and 2017, respectively. Analyzing the distribution of efficiency scores of for-profit nursing homes by years, it is evident that five of them are efficient in all years, while the number of efficient nursing homes decreased from ten to eight in the period 2015-2017, and then increased to 12 in 2018 and finally declined to eight efficient nursing homes in 2019. These nursing homes are used to create an efficient frontier against which all other nursing homes are compared. Namely, those having scores lower than one, are deemed as inefficient and they can improve their efficiency by reducing their inputs. For example, the most inefficient nursing home in 2019, $\mathrm{NH} 2$, needs to reduce inputs by $33.48 \%((1-0.6652) \times 100)$ to improve its efficiency. However, according to Table 3 , it is possible to analyze only relative efficiency due to the efficient frontier in one observed year. For example, it is possible that NH10 improved efficiency in 2018 in relation to 2017 by reducing inputs, but other NHs, especially those who were efficient, also 
improved their relative efficiency, making NH10 even more relatively inefficient. In that possible case, the efficient frontier, defined by efficient NHs, shifted higher in 2018.

\begin{tabular}{|c|rrrrr|}
\hline DMUs & 2015 & 2016 & 2017 & 2018 & 2019 \\
\hline \hline NH1 & 1 & 1 & 1 & 1 & 1 \\
NH2 & 0.9415 & 1 & 0.8634 & 0.9011 & 0.6652 \\
NH4 & 0.9995 & 1 & 1 & 1 & 1 \\
NH5 & 1 & 0.6060 & 0.6865 & 0.8059 & 0.9124 \\
NH6 & 1 & 1 & 1 & 1 & 0.7231 \\
NH7 & 0.8599 & 0.7960 & 0.6507 & 0.9076 & 0.8042 \\
NH8 & 1 & 1 & 1 & 1 & 1 \\
NH9 & 1 & 0.8290 & 0.7771 & 1 & 0.7346 \\
NH10 & 1 & 1 & 1 & 1 & 1 \\
NH12 & 0.8420 & 0.9560 & 0.9667 & 0.9491 & 0.9798 \\
NH13 & 0.9015 & 0.5750 & 0.8813 & 1 & 1 \\
NH14 & 0.8020 & 0.9260 & 1 & 1 & 0.9925 \\
NH15 & 1 & 1 & 0.9954 & 1 & 0.8823 \\
NH6 & 1 & 0.9550 & 0.9979 & 1 & 1 \\
\% of efficient DMUs & 1 & 1 & 1 & 1 & 1 \\
No. of inefficient DMUs with & 1 & 1 & 1 & 1 & 1 \\
above average efficiency & 1 & 3 & 3 & 0 & 2 \\
Minimum & 0.9592 & 0.9152 & 0.9262 & 0.9727 & 0.9184 \\
Maximum & 10 & 9 & 8 & 12 & 8 \\
Standard deviation & 0.802 & 0.575 & 0.6507 & 0.8059 & 0.6652 \\
Mean efficiency & 1 & 1 & 1 & 1 & 1 \\
No. ef eficient DMUs & 0.0684 & 0.1417 & 0.1202 & 0.0558 & 0.1191 \\
\hline
\end{tabular}

Table 3: Relative efficiency scores of Croatian for-profit nursing homes and their distribution.

To eliminate one limitation of DEA, which refers to calculating cross-sectional efficiency values, the next step in this research, was to evaluate total factor productivity change across years. Precisely, MI is examined using an input-oriented BCC model, i.e. assuming variable returns to scale. Moreover, the total factor productivity measure is decomposed into technical efficiency change and technological change. Hence, Table 4 shows MI efficiency averages for 16 Croatian for-profit nursing homes for the whole period 2015-2019. I.e., besides presenting total factor productivity change (TFPCH) Table 4 presents technical efficiency change (EFFCH) and technological change (TECHCH).

Over the analyzed period, the total factor productivity change of Croatian for-profit nursing homes is found to be at 1.1267 , which presents an increase in productivity. Namely, values of the MI and its component greater than 1, equal to 1, or less than 1, indicate progress, no change, or regress, respectively. Moreover, the aforementioned increase in productivity arises from a technical efficiency decrease and an increase in technological change. Namely, EFFCH was 0.9979, while TECHCH was established at 1.1316. The highest productivity increase occurred in $\mathrm{NH} 1$ which is associated with an increase in technological change in service delivery referring to innovation, i.e. this for-profit nursing home shift an efficient frontier to a higher level. On the other hand, NH4 experienced the most significant decline. Namely, it increased in technical change, i.e. technical efficiency reflecting catch-up effect (EFFCH is equal to 1.0113) but the aforementioned decline resulted from a decline in technological change, reflecting a decline in innovation (TECHCH is equal to 0.7860). 


\begin{tabular}{|c|rrr|c|rrr|}
\hline DMUs & EFFCH & TECHCH & TFPCH & DMUs & EFFCH & TECHCH & TFPCH \\
\hline \hline NH1 & 1.0000 & 3.0486 & 3.0486 & NH9 & 1.0000 & 1.0522 & 1.0522 \\
NH2 & 0.9269 & 1.0065 & 0.9294 & NH10 & 1.0402 & 1.0035 & 1.0406 \\
NH3 & 1.0001 & 1.0320 & 1.0321 & NH11 & 1.0763 & 0.9779 & 0.9765 \\
NH4 & 1.0113 & 0.7860 & 0.8309 & NH12 & 1.0567 & 1.0629 & 1.1227 \\
NH5 & 0.9308 & 0.9473 & 0.8950 & NH13 & 0.9706 & 1.0474 & 1.0174 \\
NH6 & 1.0060 & 1.0126 & 1.0073 & NH14 & 1.0005 & 1.0286 & 1.0321 \\
NH7 & 1.0000 & 0.9396 & 0.9396 & NH15 & 1.0000 & 1.0371 & 1.0371 \\
NH8 & 0.9470 & 0.9041 & 0.8463 & NH16 & 1.0000 & 1.2201 & 1.2201 \\
& & & & Mean & 0.9979 & 1.1316 & 1.1267 \\
\hline
\end{tabular}

Table 4: Total factor productivity change of for-profit nursing home in Croatia, 2015-2019.

Finally, Table 5 shows aggregate mean productivity change for 16 Croatian for-profit nursing homes and each pair of years.

\begin{tabular}{|c|rr|rr|rr|}
\hline & \multicolumn{2}{|c|}{ EFFCH } & \multicolumn{2}{c|}{ TECHCH } & \multicolumn{2}{c|}{ TEPCH } \\
Year & Mean & \% change & Mean & \% change & Mean & \% change \\
\hline \hline 2016 & 0.9566 & -4.3406 & 1.5854 & 58.5375 & 1.5471 & 54.7050 \\
2017 & 1.0260 & 2.5969 & 0.8805 & -11.9519 & 0.8942 & -10.5775 \\
2018 & 1.0639 & 6.3906 & 1.0496 & 4.9644 & 1.1089 & 10.8881 \\
2019 & 0.9451 & -5.4925 & 1.0110 & 1.1031 & 0.9568 & -4.3206 \\
Overal mean & 0.9979 & -0.2114 & 1.1316 & 13.1633 & 1.1267 & 12.6738 \\
\hline
\end{tabular}

Table 5: Total factor productivity change over the period 2015-2019

As it is obvious from the last row of the last column, productivity on average increased by $12.67 \%$ over the analyzed period. This is the result of an increase in technological change by $13.16 \%$, rather than technical efficiency $(-0.21 \%)$. More precisely, Croatian for-profit nursing homes on average improved their technology over the analyzed period, while they experienced a minor decrease in their relative technical efficiency. The most significant increase in productivity was observed in 2016 in relation to 2015, and the reason for this increase was the increase in technological change by $58.54 \%$ which shifted the frontier to a higher level. The most significant decline in total factor productivity occurred in the next analyzed period (2016-2017) due to the decline in technological change by $11.95 \%$, but an increase in technical efficiency by $2.6 \%$ also occurred, which positively contributed to the productivity change.

\section{Conclusion}

Demographic changes and various sociological changes increase the demand for nursing homes, and since this service can be provided by the private sector, opening a for-profit nursing home seems to be a legitimate investment decision. Therefore, this research aims to analyze the efficiency of for-profit nursing homes. Since Croatia belongs to the group of European countries with a negative demographic trend (especially in the context of aging) and because respective policymakers announced the abolition of family homes for the elderly as an alternative form of investment in this sector, the focus of this analysis in on Croatian for-profit nursing homes. Namely, the economic strength and impact of this form of care for the elderly will most likely increase.

Therefore, the changes in productivity in a sample of for-profit nursing homes in Croatia are examined from 2015 to 2019 . To estimate different kinds of efficiencies changes, precisely 
in order to estimate technological change and technical efficiency changes, the Malmquist-DEA performance measure was chosen for this analysis. Obtained results demonstrate that nursing homes in our sample experienced an increase in the total factor productivity by $12.67 \%$ in the analyzed period. Furthermore, technological innovation shifted the relative efficient frontier to a higher level (TECHCH is equal to 13.1633) while technical efficiency declined, stressing managerial relative inefficiency which resulted in a way that analyzed Croatian for-profit nursing homes failed to catch up with the best production frontier. Although the provision of services in nursing homes is labor intensive, technological innovation is complementary to the labor force, hence it increases labor productivity. Finally, the first step to increase pure technical efficiency was to detect efficient nursing homes, which represent the reference set for inefficient ones.

However, the presented analysis has its limitations and future research on this subject will be directed towards eliminating the downsides of this paper. Namely, the presented analysis is formed in line with the theoretical framework, but also respects the limitations of available data. Therefore, the depth of the future analysis will be increased by gathering and implementing additional input and output variables (such as the number of beds and the number of medical and non-medical staff). Furthermore, future research will include nursing homes from different countries and will provide a comparison of the efficiency of both for-profit and non-profit nursing homes. Finally and most importantly, using the two-stage DEA could contribute to better understanding of the circumstances that affect efficiency and improve recommendations for decision-makers, both in nursing homes and for policymakers.

\section{References}

[1] Al-Refaie, A., Najdavi, R., Al-Tahat, M. D. and Bata, N. (2015). Window analysis and Malmquist index for assessing efficiency in a pharmaceutical Industry. Proceedings of the World Congress on Engineering. London: U.K., 1, 132-136. http://www. iaeng.org/publication/WCE2015/WCE2015_ pp132-136.pdf

[2] Chen, Y.-S. and Chen, B.-Y. (2011). Applying DEA, MPI, and grey model to explore the operation performance of the Taiwanese wafer fabrication industry. Technological Forecasting and Social Change, 78(3), 536-546. doi: 10.1016/j.techfore.2010.04.013

[3] Croatian Bureau of Statistics. (2021). Women and Men in Croatia. https://www.dzs.hr/Hrv_ Eng/menandwomen/men_and_women_2021.pdf [Accessed 29/10/21]

[4] European Commission.(2018). The Silver Economy. http://publications .europa.eu/resource/ cellar/2dca9276-3ec5-11e8-b5fe-01aa75ed71a1.0002.01/D0C_1 [Accessed 24/09/21]

[5] Hrvatska gospodarska komora. (2021). Digitalna komora. https://digitalnakomora.hr/home [Accessed 10/05/21]

[6] Gandhi, A. V. and Sharma, D. (2018). Technical efficiency of private sector hospitals in India using data envelopment analysis. Benchmarking: An International Journal, 25(9), 3570-3591. doi: 10.1108/bij-06-2017-0135

[7] Gardijan, M. and Kojić, V. (2012). DEA-based investment strategy and its application in the Croatian stock market. Croatian Operational Research Review, 3(1), 203-212. https://hrcak. srce.hr/96818

[8] Hynes, S. Mateo-Mantecón, I., O'Connor, E. and Tsakiridis, A. (2020). Relative size and technical efficiency in peripheral port markets: Evidence from Irish and North Atlantic Spanish ports. Maritime Economics and Logistics, 22(3), 383-402. doi: 10.1057/s41278-019-00119-5

[9] Institute of Gerontology. (2021). Definition of Gerontology. https://iog.publichealth.uga.edu/ what-is-gerontology [Accessed 04/10/21]

[10] International Society for Gerontechnology. (2021). Gerontechnology. https://www . gerontechnology.org/about.html [Accessed 04/10/21]

[11] Kleinsorge, I. K. and Karney, D. F. (1992). Management of nursing homes using data envelopment analysis. Socio-Economic Planning Sciences, 26(1), 57-71. doi: 10.1016/0038-0121(92)90026-2

[12] Kordić, L. and Višić, J. (2021). Efficiency of Croatian nursing homes - DEA analysis. Proceedings of the 16th International Symposium on Operations Research in Slovenia, 377-382. 
http://fgg-web.fgg.uni-lj.si/ /sdrobne/sor/SOR'21\%20-\%20Proceedings.pdf

[13] Kutlar, A., Kabasakal, A. and Babacan, A. (2015). Dynamic efficiency of Turkish banks: A DEA window and Malmquist index analysis for the period of 2003-2012. Sosyoekonomi, 23(24), 71-97. doi:10.17233/se.09289

[14] Luasa, S. N., Dineen, D. and Zieba, M. (2018). Technical and scale efficiency in public and private Irish nursing homes - a bootstrap DEA approach. Health Care Management Science, 21(3), 326347. doi: 10.1007/s10729-016-9389-8

[15] Ministarstvo rada, mirovinskog sustava, obitelji i socijalne politike. (2021). Adresari. https:// mrosp.gov.hr/adresari/11829 [Accessed 04/09/21]

[16] Mogha, S. K., Yadav, S. P. and Singh, S. P. (2012). Performance evaluation of Indian private hospitals using DEA approach with sensitivity analysis. International Journal of Advances in Management and Economics, 1(2), 1-12. doi: 10.31270/ijame/01/02/2012/01

[17] Mogha, S. K., Yadav, S. P. and Singh, S. P. (2014). New slack model based efficiency assessment of public sector hospitals of Uttarakhand: State of India. International Journal of System Assurance Engineering and Management, 5(1), 32-42. doi: 10.1007/s13198-013-0207-0

[18] Moshiri, H., Aljunid, S. M. and Amin, R. M. (2010). Hospital efficiency: Concept, measurement techniquers and review of hospital efficiency studies. Malaysian Journal of Public Health Medicine, 10(2), 35-43. https://www.mjphm.org.my/mjphm/journals/Volume10.2/5.

[19] Ozcan, Y. A. (2008). Health care benchmarking and performance evaluation: An assessment using data envelopment analysis (DEA). New York: Springer. doi:10.1007/978-0-387-75448-2

[20] Prior, D. (2006). Efficiency and total quality management in health care organizations: A dynamic frontier approach. Annals of Operations Research, 145(1), 281-299. doi: 10.1007/s10479-006-00356

[21] Pučki pravobranitelj - Republika Hrvatska. (2021). Izvješće za 2020 - Umirovljenici i starije osobe. https://www.ombudsman.hr/hr/umirovljenici-i-starije-osobe-2 [Accessed 26/09/21]

[22] Pulina, M. and Santoni, V. (2018). A two-stage DEA approach to analyse the efficiency of the hospitality sector. Tourism Economics, 24(3), 352-365. doi: 10.1177/1354816618758733

[23] Sánchez-Ortiz, J., Garcia-Valderrama, T., Rodríguez-Cornejo, V. and Cabrera-Monroy, F. (2021). DEA window analysis and Malmquist index to assess efficiency and productivity in the Spanish electricity sector. International Journal of Energy Sector Management, 15(4), 765-788. doi: 10.1108/ijesm-03-2019-0020

[24] Sun, C.-C. (2011). Assessing Taiwan financial holding companies' performance using window analysis and Malmquist productivity index. African Journal of Business Management, 5(26), 10508-10523. doi: $10.5897 /$ ajbm11.438

[25] Tran, A., Nguyen, K.-H., Gray, L. and Comans, T. (2019). A systematic literature review of efficiency measurement in nursing homes. International Journal of Environmental Research and Public Health, 16(12), 1-18. doi: 10.3390/ijerph16122186

[26] UNCTAD. (2019). Population structure by gender and age-group, annual, 1950-2050. https://unctadstat.unctad.org/wds/TableViewer [Accessed 24/09/21]

[27] Veloso, A. S, Vaz, C. B. and Alves, J. (2018). Determinants of nursing homes performance: The case of Portuguese Santas Casas da Misericórdia. Operational Research - Springer Proceedings in Mathematics and Statistics book series, 393-409. doi: 10.1007/978-3-319-71583-4_26

[28] Vlada Republike Hrvatske. (2021). Nacionalni plan oporavka i otpornosti 2021.-2026. https://planoporavka.gov.hr/UserDocsImages/dokumenti [Accessed 29/10/21]

[29] Worthington, A. C. (2004). Frontier efficiency measurement in healthcare: A review of empirical tehniques and selected applications. Medical Care Research and Review, 61(2), 135-170. doi: $10.1177 / 1077558704263796$

[30] Zheng, X., Chau, K.-W. and Hui, E. C. M. (2011). Efficiency assessment of listed real estate companies: An empirical study of China. International Journal of Strategic Property Management, 15(2), 91-104. doi: 10.3846/1648715X.2011.582739 